\title{
Serviks Kanserinde Radyoterapi Tedavisinin Yeri ve Önemi
}

\author{
Özlem YETMEN $N^{1, *}$,Caner AKTAŞve B. Hakan BAKKAL ${ }^{1}$ \\ ${ }^{1}$ Bülent Ecevit Üniversitesi, Radyasyon Onkolojisi Anabilim Dall, Zonguldak, Türkiye \\ "e-mail: dryetmen@gmail.com
}

\begin{abstract}
Özet
Serviks kanseri jinekolojik kanserler içinde sıklık açısından ikinci sırada yer almaktadır. Radyoterapi, yaklaşık yüzyıllık süreçte serviks kanseri tedavisinde kullanılmaktadır. Özellikle de lokal ileri hastalıkta ilk tedavi seçeneği olmuştur. Tek başına eksternal radyoterapi büyük tümörlerde düşük kontrol oranı sağlamaktadır. Serviks kanserinde brakiterapinin de kullanılması ile büyük tümörlerin kontrol oranları yükselmiştir. Son yıllarda radyoterapinin etkinliğini arttırmak amacıyla kemoradyoterapinin birlikte kullanımı gündeme gelmiştir. Kemoradyoterapi çalışmalarında en sık sisplatin, 5-FU, mitomisin-C ve hidroksiüre kullanılmıștır. Bu çalışmaların sonucunda kemoradyoterapinin uygulandığı randomize çalışmalarda görülmüştür ki serviks kanserinde kemoradyoterapi uygulanmasının, özellikle de sisplatinin sağkalım avantajı sağladığı gösterilmiştir.
\end{abstract}

Anahtar Kelimeler: Serviks kanseri, radyoterapi, kemoradyoterapi

\begin{abstract}
Cervical cancer ranks second in terms of frequency of gynecological cancers. Radiation therapy used to treat cervical cancer in the process nearly a century. In particular, became first-line treatment in locally advanced disease. Provides a low control rate in large tumors with external beam radiotherapy alone. Large tumors with the use of brachytherapy in cervical cancer control rates were also increased. The most common work chemoradiotherapy cisplatin, 5-FU and mitomycin-C, hydroxyurea, is used. Suffered as a result of these studies, randomized trials that applied chemoradiotherapy implementation of chemoradiation in cervical cancer, especially cisplatin shown to provide a survival advantagein recent years, in order to increase the effectiveness of radiotherapy with chemoradiotherapy was introduced.
\end{abstract}

Keywords: Cervical Cancer, Radiotherapy, Chemoradiotherapy 


\section{Giriş}

Serviks kanseri jinekolojik kanserler içinde sıklık açısından ikinci sırada yer almaktadır (Lehman ve ark., 2001). Serviks kanserinde, tedavi yönteminin belirlenmesinde tümöre ait özelliklerin bilinmesinin yanı sıra yayılım şekli ve yollarının da bilinmesi gerekir. Serviks kanseri direkt invazyon, lenfatik yol ve nadir olarak da hematojen yol ile yayilır. Transformasyon zonundan kaynaklanan invaziv karsinom bazal membranı aştıktan sonra stromayı infiltre ederek direkt yayılımla çevre dokulara ve organlara doğru ilerler. En sık parametrium ve vagina infiltrasyonu gözlenirken daha ileri evrede mesane ve rektuma da invazyon oluşturmaktadır (Perez Ca,1981). Pelvik lenf nodlarının tutulum riski, evre III'de \%46-66, evre II'de \%32-45 ve evre I'de \%11-18 arasindadır (Inoue ve ark.,1984; Tanaka ve ark., 1984). Paraaortik lenf nodlarının tutlumu da önemli bir faktördür. Paraaortik nodların tutulum sıklığı evre I-II'da \%0-33, evre III'de \%46 ve üzeri, evre IV'de \%57 ve daha fazlasıdır (Wharton ve ark.,1977). Serviks kanserinde daha nadir görülen hematojen yayılım ile uzak organ metastaz yerleri sıklık sırası ile akciğer, kemik, karaciğer ve beyindir (Badib ve ark.,1968; Carlson ve ark. 1967).

Serviks kanserinin en sık semptomu ağrısız metroraji ve postkoital kanamadır. Kanama lekelenme tarzında ve metroraji şeklinde olur. Hipogastrik sinir ve lumbosakral pleksusa büyümüş pelvik lenf nodlarının basısı sonucunda oluşan ağrı; genellikle lomber ve gluteal bölgede oluşur. İlerlemiş hastalık belirtileri, üretelerin tutulmasına bağlı hidronefroz, pelvik duvar ve siyatik sinirlerin tutulumuna bağlı yana ve bacağa vuran ağrıdır. Hastaların çoğu mesane ve rektum tutulumuna bağlı dizüri, rektal kanama veya konstipasyondan şikayetcidirler. Temelde tümör büyüklüğü ve pelvisteki yayılımı esas alan bir klinik-patolojik evreleme sistemi olan FIGO evreleme sistemi kullanılır (International Federation of Gynecology and Obstetrics.1995).

Serviks kanserinde uygun bir evreleme için, tedavi başlamadan önce genel anestezi altında bimanuel pelvik ve rektal muayene yapılması gerekir. Jinekolojik muayenede şüpheli mesane veya rektum invazyonu varlığında biyopsi ile doğrulanması gerekmektedir. Lenf nodu değerlendirmede bilgisayarlı tomografi (BT), magnetik rezonans (MRG), lenfanjiografi ve pozitron emisyon tomografi (PET) görüntüleme yöntemleri kullanılabilir. GOG tarafından yapılan bir çalışmada paraaortik lenf nodu tutulumunun saptanmasında BT ve lenfanjiografi karşılaştırılmış ve BT'nin tanısal duyarlılı̆ğının \%96 olduğu saptanmıştır (Heller ve ark.,1990). Bunun yanında lenfanjiografi de paraaortik lenf nodlarının değerlendirilmesine yönelik bir görüntüleme tekniğidir fakat invaziv bir girişim olması nedeni ile günümüzde kullanımı azalmıştır (National Institues of Health Concensus Development Conference Statement on Cervical Cancer,1999). MRG ise tümör yayılımının belirlenmesinde yardımcı bir yöntem olarak kullanılmaktadır (Russel Ah ve ark.,1992).Günümüzde kullanımı artmış olan PET görüntüleme yönteminde ise aortik ve pelvik lenf nodlarını ve metastatik hastalı̆̆ saptamada BT ve MRG'ye göre daha üstün olduğu tespit edilmiştir. Grisby ve arkadaşlarının yaptığı çalışmada, PET ve BT karşılaştırılmış, BT'nin büyümüş pelvik lenf nodlarını saptamadaki tanısal doğruluğunun $\% 20$, aortik lenf nodlarını saptamadaki tanısal doğruluğunun ise \%7 olduğu bulunmuştur. $\mathrm{Bu}$ oran PET için sırasıyla $\% 67$ ve $\% 21$ olarak tespit edilmiştir. Bu çalışmada ayrıca PET ile pozitif lenf nodlarının saptanması hastalıksız sağkalımı olumsuz yönde etkilediği görülmüştür (Grisby ve ark., 2001).

\section{Serviks Kanserinde Radyoterapi Tedavisi}

Radyoterapi, yaklaşı yüzyıllık süreçte serviks kanseri tedavisinde kullanılmaktadır. Özellikle de lokal ileri hastalıkta ilk tedavi seçeneği olmuştur. Ancak bulky tümör varlığ 1 ve normal doku toksisitesi nedeniyle yüksek dozlara çıkılamaması tedavinin başarısını azaltmaktadır (Lehman ve ark., 2001; Robert ve ark., 2000). Radyoterapi 1900'lü yılların başında intrakaviter radyum tedavisi ile serviks kanserinde uygulanmaya başlamıştır (Horiot ve ark.,1988 ). Hamberger ve Fletcher'in yalnız radyum ile tedavi ettiği küçük tümörlü evre IB olgularda nüks oranlarının azaldığı saptanmıştır (Hamberger ve ark.,1978 ). Tek başına eksternal radyoterapi büyük tümörlerde düşük kontrol oranı sağlamaktadır. Serviks kanserinde brakiterapinin de kullanılması ile büyük tümörlerin kontrol oranları 
yükselmiştir. Böylece eksternal ve intrakaviter ışınlama standart tedavi yöntemi haline gelmiştir. Radyoterapinin etkisini arttırmak amacıyla eş zamanlı kemoradyoterapide hidroksiüre, 5-FU, sisplatin ve mitomisin gibi ajanlar kullanılmıştır. Yapılan randomize çalışmaların sonucunda, özellikle sisplatinin sağkalım avantajı sağladığı gösterilmiştir (Rose Pg, 1994; Rose ve ark.,199; Pignon ve ark., 2000; Morris ve ark., 1999).

Eksternal pelvik radyoterapide Cobalt 60 aygıtı kullanılırken günümüzde lineer hızlandırıcılar tercih edilmektedir. Günümüzdeki onkolojik yaklaşım normal doku toleransını geçmeden riskli bölgelere yeterli dozun verilmesidir. Serviks kanserinde lenf nodlarındaki mikrosopik hastalık, genellikle 45-50 Gy'lik eksternal radyoterapi dozu ile kontrol edilebilir. Evre IB-IVA hastalarda eksternal, internal, ana iliak ve presakral lenf nodları da ışınlanmalıdır. Alt alanın sınırı, vaginal yayılım yoksa obturator foramenin alt sınırına, vaginal tutulum varsa introitusa kadar uzatılmalidır. Kemik pelviste $1.5-2 \mathrm{~cm}$.lik lateral sınır yeterlidir. Eğer posterior vaginal duvar tutulumu varsa, perirektal lenf nodları da ışınlanmalıdır. 1/3 Alt vajen tutulumunda inguinal lenf nodları da alan içine dahil edilmelidir. External radyoterapi sonrasında, parametrial tutulum hala varsa, bu bölgeye 6-10 Gy ek doz uygulanmalıdır. Konformal radyoterapide ise özellikle riskli organlar belirlenir, daha sonra bölgesel lenf nodları tanımlanır (Dietmar ve ark.,2008; Akine ve ark.,1983). Riskli organlar içinde; ince barsak, rektum, mesane, böbrekler ve femur başları bulunmaktadır. Radyoterapi alanları genelde 4 alanlı kutu tekniği kullanılarak, 0, 90, 180, 270 gantri açıları ile 15 MV foton 1şınları ile uygulanır (Akine ve ark.,1983)Serviks kanserlerinde eksternel radyoterapininin brakiterapi ile birlikte uygulanması önem taşır. İntrakaviter BRT'de iridyum (Ir192), kobalt (Co60) veya sezyum (Cs137) kullanılmaktadır. Bindokuzyüzlü yılların başında uygulanmaya başlanan manuel BRT, 1970'lerden sonra yerini uzaktan kumandalı sonradan yüklemeli uygulamalara bırakmıştır. Yüklemeli brakiterapi uygulamalarında tedavi ve bakım ekibi daha az radyasyona maruz kaldığından, birçok merkezde uzaktan kumandalı yüklemeli yöntemler yaygın kullanılmaktadır. Genellikle HDR (yüksek doz hızlı)'da Ir192 ve Co60 kaynakları tercih edilir. Günümüzde birçok klinisyen HDR brakiterapiyi tercih etmektedir. Tedavi süresinin kısalığı, uzun süre yatamayacak hastalarda tedavi olanağı sağlaması, tedavi sırasında aplikatör oynama riskinin daha az olması, hospitalizasyona gerek kalmaması ve tedavi masrafının azalması, daha fazla hastayı tedavi edebilme olanağı sağlaması ve hekimlerin ve yardımcı personelin radyasyona maruziyetinin en aza indirilmesi önemli yararlarıdır (Chauvergne ve ark., 1990).

\section{Serviks Kanserinde Kemoradyoterapi Tedavisi}

İkibinli y1llara kadar serviks kanserlerinde radyoterapi ile lokal kontrol oranlar1 \%35-90 arasinda değişmekte ve nüklerin 2/3'ü radyoterapi alanını içerisinde gelişmekte idi (Lehman ve ark., 2001; Rose Pg,1994; Rose ve ark.,1999). Radyoterapinin etkinliğini arttırmak amacıyla kemoradyoterapinin birlikte kullanımı gündeme gelmiştir. Kemoradyoterapi çalışmalarında en sık sisplatin, 5-FU, mitomisin-C ve hidroksiüre kullanılmıştır. Kemoradyoterapinin uygulandığ 1 randomize çalışmaların sonuçları yayınlanmış ve serviks kanserinde kemoradyoterapi uygulanmasının, özellikle de sisplatinin sağkalım avantaj1 sağladığ1 gösterilmiştir (Rose Pg,1994; Rose ve ark.,1999; Pignon ve ark., 2000; Morris ve ark., 1999). Konkomittan kemoradyoterapi, serviks kanserinden ölüm riskini \%30-50 azaltmıştır. Bu sonuçlar nedeni ile, radyoterapi ile tedavi edilen serviks kanserli hastalara sisplatin içeren konkomittan kemoterapi uygulanması önerilmektedir (Spensley ve ark., 2008). Kemoterapi ve radyoterapinin birlikte kullanımı sinerjistik etki oluşturmakta ve tümör hücrelerinin radyasyona duyarlılığını arttırmaktadır. Radyoterapi lokorejyonel hastalığın kontrolünde etkin iken, eklenen kemoterapinin tedavi alanı dışı başarısızlıkları azaltacağı beklenmektedir. Bu bilgiler doğrultusunda haftalık sisplatin uygulamasının kabul edilebilir toksisitesi ve etkinlik oranları nedeniyle uygun bir tedavi olduğu sonucuna varılmıştır (Rose Pg,1994; Rose ve ark.,1999; Pignon ve ark., 2000; Morris ve ark., 1999; Keys ve ark.,1999; Peters ve ark., 2000).

Yapılan beş büyük çalışmada serviks kanserinde radyoterapi tedavisine kemoterapinin eklenmesi ile sağkalım avantajı sağlanmıştır. Jinekolojik Onkoloji Grubu'nun (GOG 85) yapmış olduğu çalışmada evre IIB-IVA 368 serviks kanserli hasta kontrol grubuna eksternal pelvik radyoterapi ile 2 
haftada bir $80 \mathrm{mg} / \mathrm{kg}$ hidroksiüre uygulanmış, diğer gruba ise eksternal pelvik radyoterapi ile 5Fluorourasil ve sisplatin $50 \mathrm{mg} / \mathrm{m} 2$, radyoterapinin $2 .-5$. günleri ile 29.-33. günlerinde uygulanmıştır. Sisplatin ve 5-Flurourasil alan kolda 5 yıllık yaşam oran $\% 62$, hidroksi ile radyoterapi uygulanan kolda \%50 olarak bulunmuştur. Akut gastrointestinal toksisitenin sisplatin/5-Fluorourasil uygulanan kolda daha yüksek olarak bulunmuştur (Wong ve ark.1999). Jinekolojik Onkoloji Grubu'nun (GOG 120) lokal ileri serviks kanserli olgularda sisplatin temelli 526 olguluk çalışmasında, birinci kola haftalık sisplatin $(40 \mathrm{mg} / \mathrm{m} 2-6 \mathrm{kez})$; ikinci gruba sisplatin $(50 \mathrm{mg} / \mathrm{m} 2)$ 1. ve 29 . günlerde, oral hidroksiüre $(2 \mathrm{gr} / \mathrm{m} 2) 2$ haftada bir; üçüncü gruba ise oral hidroksiüre $(3 \mathrm{gr} / \mathrm{m} 2) 2$ haftada bir uygulanmıştır.Sonuç olarak sisplatin içeren her iki grupta hidroksiüre uygulanan gruba göre progresyonsuz ve genel sağkalım oranları yüksek bulunmuştur (Whitney ve ark.,1999). Radyoterapi Onkoloji Grubunun (RTOG 90-01) faz III çalışmasında evre IB-IVA serviks kanserli olgularda bir gruba yalnız eksternal ve intrakaviter radyoterapi, diğer gruba ise sisplatin ve 5-FU ile eşzamanlı radyoterapi uygulanmış, çalışma sonucunda kemoradyoterapi uygulanan koldaki olgularda hastalıksız ve genel sağkalım oranlarının anlamlı olarak yükseldiği görülmüştür (Eifel ve ark., 2004). Jinekolojik Onkoloji Grubu'nun (GOG 123) 369 hastayı kapsayan faz III randomize çalışmada tek başına radyoterapi ve sonrasında histerektomi veya radyoterapi ile eşzamanlı sisplatin sonrasında histerektomi yapılmış. Haftalık olarak $40 \mathrm{mg} / \mathrm{m} 2$ sisplatin uygulanmış. 36 aylık takip süresi sonunda eşzamanlı haftalık sisplatin alan hastalarda tek başına radyoterapi alan gruba oranla pelvik kontrolün, hastalıksız geçen sürenin ve genel yaşam süresinin artmış olduğu belirlenmiştir. 3 yıllık yaşam oranları ise kemoradyoterapi alanlarda \%83, tek başına radyoterapi alanlarda \%74 olarak belirlenmiştir (Whitney ve ark.,1999).1991-1996 yılları arasında yapılmış olan İntergrup protokol 107 (GOG 109/RTOG 91-12/SWOG 8797) çalışmasında 243 hasta çalışmaya dahil edilmiş bir gruba histerektomi ve pelvik lenfadenektomi sonrasında radyoterapi yapılırken diğer gruba histerektomi ve pelvik lenfadenektomi sonrasında radyoterapi ile eş zamanlı sisplatin $(70 \mathrm{mg} / \mathrm{m} 2)$ ve 5 -FU $(1000 \mathrm{mg} / \mathrm{m} 2 /$ gün$)$ $(1,22,43,64$. günlerde) verilmiş. 42 aylık takip süresi sonunda kombine tedavi alan gruptaki genel yaşam süreleri ve hastalıksız geçen sürenin tek başına radyoterapi alan gruba oranla arttı̆̆ gözlenmiştir. Hesaplanmış 4 yıllık genel yaşam oranları kemoradyoterapi grubunda \%81, radyoterapi grubunda \%71 olarak belirlenmiştir. (Sundfer ve ark.,1996) Son olarak 2008 yılında yayınlanan 18 randomize çalışmayı kapsayan metaanaliz sonucunda, serviks kanserinde kemoradyoterapi uygulanmasından sonra adjuvan radyoterapi uygulanmasının toplam sağkalım süresine katkı sağladığı gösterilmiştir. Aynı zamanda sisplatin bazlı kemoradyoterapi uygulamaları ile sisplatin bazlı olmayan kemoradyoterapi uygulamalarında lokal ve uzak yinelemeleri azalttığı, hastalıksız ve genel sağkalım sürelerini arttırdığı bulunmuştur (Wong ve ark.,1999). Konkomittan kemoradyoterapi de uygun kemoterapi rejimi net olarak belirlenmemiş olmakla birlikte haftalık sisplatin ya da 5-FU ve sisplatin kombinasyonları tercih edilmektedir.

\section{Sonuç}

Serviks kanserinde radyoterapi lokal ileri evre olgular yanı sıra erken evrelerde de tercih edilmektedir. Tedavi etkinliğini arttırmak amacı ile sisplatin, 5-FU, mitomisin-C ve hidroksiüre gibi birçok kemoterapötik ajan kullanılmıştır. Serviks kanserlerinde kemoradyoterapi uygulamalarının yüksek yanıt oranları sağladığı, tek başına radyoterapiye kıyasla genel sağkalım ve hastalıksız sağkalım açısından daha üstün olduğu ve bunun yanı sıra kabul edilebilir toksisite nedeni ile bu olgularda tedavi seçeneği olarak tercih edilmelidir. 


\section{Kaynaklar}

Akine Y, Arimoto H, Ogino T, ve ark.1983. High dose rate intracavitary irradiation in the treatment of carcinoma of the uterine cervix:whole pelvis irradiation and intracavitary radium. Int. J. Radiat Oncol Biol Phys. 9:367-71.

Badib AO, Kurohara SS, Werteb JH, Pickren JW.1968. Metastasis to organs in carcinoma of the uterine cervix:influence of treatment on incidebce and distribution. Cancer. 21:434

Carlson V, Delclos L, Fletcher GH. 1967.Distant metastases in squamous-cell carcinoma of the uterine cervix. Radiology 88:961

Chauvergne J, Rohart J, Heron JF, ve ark.1990.Randomised trial of initial chemotherapy in 151 locally advanced carcinoma of the cervix (T2b-N1, T3b, M0). Bull Cancer. 77:1007-24.

Dietmar Georg, Petra Georg, Martin Hillbrand, ve ark.2008. Assessment of 1mproved organ at risk sparing for advanced cervix utilizing precision radiotherapy techniques. Strahlender Onkol.184:58691.

Eifel PJ, Winter K, Morris M, ve ark.2004. Pelvic irradiation with concurrent chemotherapy versus pelvic and para-aortic irradiation for high risk cervical cancer:an update of radiation therapy oncology group trial (Rtog) 90-01. J Clin Oncol .22:972-980.

Grisby PW, Siegel Ba, Dehdashti F. 2001. Lymph node staging by positron emission tomography in patients with carcinoma of the cervix. J Clin Gynecol. 19:3745-3749.

Hamberger AD, Fletcher GH, Wharton JT.1978. Results of treatment of early stage I carcinoma of the uterine cervix with intracavitary radium alone. Cancer. 41(3):980-985.

Heller PB, Malfenato JH, Bundy BN ve ark. 1990. Clinical-pathologic study of stage IIB, III and IVA carcinoma of the cervix: extended diagnostic evaluation for para-aortic node metastasis. Gynecol Onco.; 38:425-430.

Horiot JC, Pigneux J, Pourquer H, Scaraub S, Achielle E, Keilling R, Combes P, Rozan R, Vrousos C, Daly N.1988. Radiotherapy alone in carcinoma of the intact uterine cervix according to G.H Fletcher guidelines: a french cooperative study off 1383 cases . Int J. Radit Oncol Biol Phys;14:605-611.

Inoue T.1984. Prognostic significance of depth of invasion relating to nodal metastases, parametrial extension and cell types. a study of 628 cases with stage IB, IIA and IIB cervical carcinoma. Cancer 54: 3035

International Federation of Gynecology and Obstetrics.1995: Staging announcement figo staging of gynecologyic cancers: cervical and vulva. Int J Gynecol Cancer ; 5:319-324.

Keys HM, Bundy BN, Frederick BS ve ark. 1999.Cisplatin, radiation and adjuvant histerectomy compared with radiation and adjuvant hysterectomy for bulky stage IB cervical carcinoma. New Engl JMed. 340: 1154-1164.

Lehman M, Thomas G 2001. Is concurrent chemotherapy the new standard of care for advanced cervical cancer. Int J Gynecol Cancer 11: 87-99

Morris M, Elfel PJ, J Lu ve ark. 1999. Pelvic radiation with concurrent chemoradiotherapy compared pelvic and para-aortic radiation for high risk cervical cancer. New England Journal Of Medicine 340: 1137-1143.

National Institues Of Health Concensus Development Conference Statement On Cervical Cancer1997. Gynecol Oncol; 66:351-361.

Perez CA, Camel HM, Aksin F, Breaux S 1981. Endometrial extension of carcinoma of the uterine cervix:a prognostic factor that may modify staging. Cancer. 48:170 
Peters WA, Liu PY, Barret RJ ve ark. 2000. Concurrent chemotherapy and pelvic radiation therapy alone as adjuvant after radical surgery in high-risk early stage cancer of risk. Journal Of Clinical Oncology; 18:1606-1613.

Pignon JP, Bourhis J, Domenge C, Designe L on Behalf of The Mach-Nc Collaborative Group. 2000. Chemotherapy added to locoregional treatment for head and neck squamous cell carcinoma: three meta-analyses of updated individual data. Lancet. 355: 949-945.

Robert KB, Urdaneta N, Vera R ve ark.2000. Interim results of a randomized trial of mitomycin-c as an adjunct to radical radiotherapy in the treatment of locally advanced squamoz cell carcinoma of the cerviks. Int J Cancer , 90:206-223

Rose PG, Bundy BN, Watkıns EB ve ark.1999. Concurrent cisplatin-based radiotherapy and chemotherapy for locally advanced cervical cancer. New Engl Med 340: 1144-1153.

Rose PG.1994. Locally advanced cervical carcinoma the role of chemoradiation. Semin Oncol. 21: 4753.

Russel AH, Walter JP, Anderson NW ve ark.1992. Sagittal magnetic resonance imaging in the design of lateral radiation treatment portals for patients with locally advanced squamous cancer of the cervix. Int J Radiat Oncol Biol Phys 23:449-455.

Spensley S ve ark. 2008. Clinical outcome for chemotadiotherapy in carcinoma of the cervix. Clinical Onco.

Sundfer K, Trope CG, Hogberg T ve ark.1996. Radiotherapy and neoadjuvant chemotherapy for cervical carcinoma. a randomized multicenter study of sequential cisplatin and 5-flourouracil and radiotherapy in advanced cervical carcinoma stage 3B and 4A. Cancer.77: 2371-2378.

Tanaka Y, Sawada S, Murata T.1984: Relationship between lymph node metastases and prognosis in patients irradiated postoperatively for carcinoma of the uterine cervix. Acta Radiol. 23: 455

Wharton JT, Jones HW III, Day TG JR ve ark.1977. Preirrdadiation celiotomy and extended field 1rradiation for invasive carcinoma of the cervix. Obstet Gynecol. 49:333

Whitney CW, Sause W, Bundy BN ve ark.1999. A randomized comparison of fluorourasil plus cisplatin versus hydroxyurea as an adjunct to radiation therapy in stages IIB-IVA carcinoma of the cervix with negative para-aortic lymph nodes. a gynecologic oncology group and southwest oncology group study. J Clin Oncol.17:1339-1342.

Whitney CW, Sause W, Bunndy BN ve ark. 1999. Randomized comparison of flurouracil plus cisplatin versus as an adjunct to radiation therapy in stage IIIVA carcinoma of the cervix with negative paraortic lymph nodes. A gynecologic oncology group and south oncology group study. J Clin Oncol. 17:1339-1348.

Wong LC, Ngan HYS, Cheung ANY ve ark.1999. Chemoradiation and adjuvant chemotherapy in cervical cancer. Journal of Clinical Oncology.17: 2055-2060. 